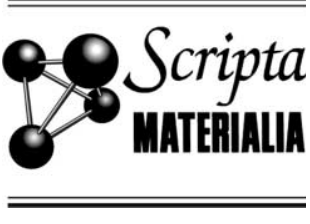

Scripta Materialia 48 (2003) 207-211

www.actamat-journals.com

\title{
Martensitic transformation in Pd-rich Fe-Pd-Pt alloy
}

\author{
Taishi Wada, Tetsuya Tagawa, Minoru Taya * \\ Department of Mechanical Engineering, Center for Intelligent Materials and Systems, University of Washington, Box 352600, \\ Seattle, WA 98195-2600, USA
}

Received 2 April 2002; received in revised form 22 July 2002; accepted 23 July 2002

\begin{abstract}
The fct martensite morphology and the martensite transformation temperatures are examined for Pd-rich Fe-Pd-Pt

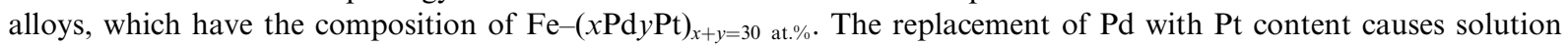
hardening. The shape memory effects are investigated below the Af temperatures. Above the Af temperatures, the stress induced martensite in several grains completely disappeared due to the reverse transformation by unloading.

(c) 2002 Acta Materialia Inc. Published by Elsevier Science Ltd. All rights reserved.
\end{abstract}

Keywords: Fe-Pd-Pt alloy; Martensite transformation; Stress induced martensite transformation; Stress-strain relation

\section{Introduction}

Ferromagnetic shape memory alloys (FSMA) have recently attracted considerable attention for their applicability as a magnetic switching actuator material. Several alloy systems for FSMA have been investigated [1-8]. Among these alloy systems, Fe-Pd alloy has the following advantages: large magnetization, small thermal hysteresis of the martensite transformation, easy to control the martensite transformation (Ms) temperature with alloy composition and high ductility, thus processable by the existing route. The high ductility of $\mathrm{Fe}-\mathrm{Pd}$ alloy sometimes brings the slip deformation which competitively occurs during the stress induced transformation. The third alloy element

\footnotetext{
${ }^{*}$ Corresponding author. Tel.: +1-206-685-2850; fax: +1-206685-8047/616-4088.

E-mail address: tayam@u.washington.edu (M. Taya).
}

possibly improves the softness of $\mathrm{Fe}-\mathrm{Pd}$ alloy. Addition of the third element usually gives a strong influence on the martensite transformation itself and it sometimes hampers the thermoelastic transformation.

In this paper, the influence of $\mathrm{Pt}$ additions as a third alloy element for $\mathrm{Fe}-\mathrm{Pd}$ on the martensite transformation is investigated. In the present work, the alloy compositions of $\mathrm{Fe}-(x \mathrm{Pd} y \mathrm{Pt})_{x+y=30}$ at.\% are taken on the basis of the Fe-30at.\%Pd alloy. The thermally induced and the stress induced fccl fct martensite transformations are examined for these alloys. In the Fe-Pd alloy system, a bct martensite of the lower temperature phase instead of the fct phase has been reported [7]. The effect of the $\mathrm{Pt}$ addition on the bct transformation should be considered, because the non-thermoelastic behavior of the bct martensite spoils the reversible transformation of fcc/fct phases. The mechanical properties, the temperature dependency of Young's modulus and the permanent strain after 
the transformation recovery are also studied in this paper. The dependency of Young's modulus on temperature was reported as the lattice softening in Fe-Pd alloy $[9,10]$. This gives a benefit of the large displacement for an actuator application. Resistance to slip deformation in Fe-Pd-Pt alloys is also discussed by comparison with the $\mathrm{Fe}-\mathrm{Pd}$ alloy.

\section{Experimental procedure}

The alloy compositions used are $\mathrm{Fe}-$ $(x \mathrm{Pd} y \mathrm{Pt})_{x+y=30}$ at. $\%$ and $y$ values are taken for 0,1 , 2, 4, 6 and 8 at.\%. Weighted iron granular $(99.98 \%)$, palladium powder $(99.95 \%)$ and platinum powder $(99.98 \%)$ were melted together in an arc furnace with a purified argon atmosphere. After a homogenizing heat treatment at $1523 \mathrm{~K}$ for $90 \mathrm{ks}$, the alloys were rolled into a plate with thickness of $0.8 \mathrm{~mm}$ and machined into the specimen with $2 \mathrm{~mm}$ in width and $40 \mathrm{~mm}$ in length. The specimens were annealed at $1523 \mathrm{~K}$ for $45 \mathrm{ks}$ and subsequently quenched.

The martensite transformation temperatures were measured by differential scanning calorimeter (DSC). The optical microscope observation was also adopted to determine the martensite transformation (Ms) temperature to keep the reliability. The optical measurements were repeatedly carried out in several observation frames on the polished specimen surface with a thermocouple. The difference of both measurements was found within $3{ }^{\circ} \mathrm{C}$.

Tensile tests were performed on the specimens contained in an environmental chamber using Instron 8562 under a constant stress rate, two stress rates of 0.5 and $5 \mathrm{MPa} / \mathrm{s}$ adopted for the measurements of the elastic modulus and the nonlinear stress/strain relations, respectively. The specimen temperature was measured using a thermocouple attached on the specimen surface. Continuous flow of cooled nitrogen gas into the chamber controlled the specimen temperature within $1{ }^{\circ} \mathrm{C}$. The strain response was measured with strain gauges on the two surfaces of the specimen. The microstructure of the specimen subjected to various thermomechanical conditions was observed with CCD camera and it was continuously recorded in videotape during the tensile test. For the compositions with over 6 at.\% Pt, tensile tests could not be done due to too low a Ms temperature.

\section{Results and discussion}

Fig. 1 shows the Ms (fcc/fct) temperatures for each alloy with $\mathrm{Fe}-(x \mathrm{Pd} y \mathrm{Pt})_{x+y=30}$ at.\% composition. The Ms temperatures decided by optical observations agree well with the DSC results. In the Fe-Pd binary system, the decrease of the Pd content brings the high Ms temperature [7]. However, the results in Fig. 1 show that the replacement of $\mathrm{Pd}$ with Pt decreases the Ms temperature. It means that the Pt alloying strongly contributes to lower the Ms temperature. The all martensite transformation temperatures, Ms, Mf, As and Af, measured by DSC are also shown in Fig. 1. The hysteresis widths $\mathrm{Af}-\mathrm{Ms}$ for $\mathrm{Fe}-\mathrm{Pd}-\mathrm{Pt}$ alloys are about $5{ }^{\circ} \mathrm{C}$, which is same as that for $\mathrm{Fe}-$ 30at.\%Pd.

The representative martensite morphologies for $\mathrm{Fe}-(x \mathrm{Pd} y \mathrm{Pt})_{x+y=30}$ at. $\%$ alloys are shown in Fig. 2 where the observation temperature for each photo is set lower than the martensite finish (Mf) temperature. No major differences are observed in fct martensite morphology among the six alloys investigated. In Fe-22at.\%Pd8at.\%Pt alloy, however, the area of fct martensite phase is smaller.

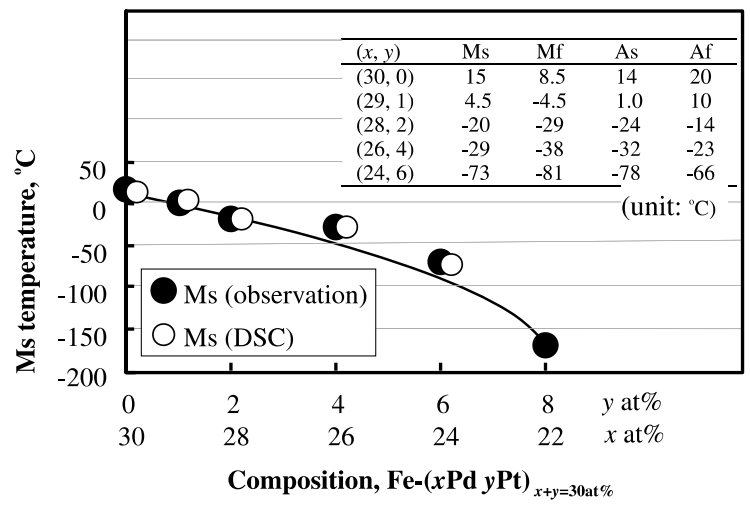

Fig. 1. Dependency of fcc/fct Ms temperature on Fe-Pd-Pt alloy composition and all transformation temperatures, Ms, Mf, As and Af measured by DSC and optical observation. 


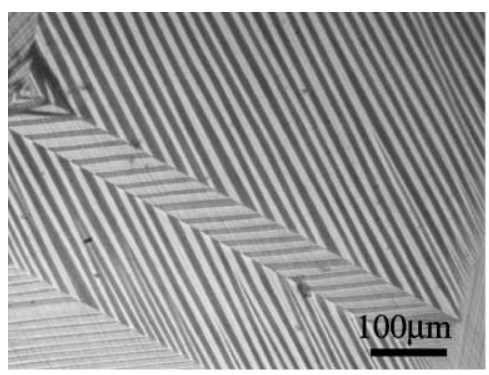

(a) Fe-30at $\% \mathrm{Pd}$

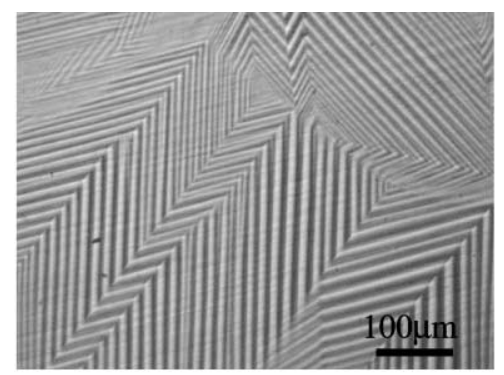

(b) Fe-28at $\%$ Pd 2at $\% \mathrm{Pt}$

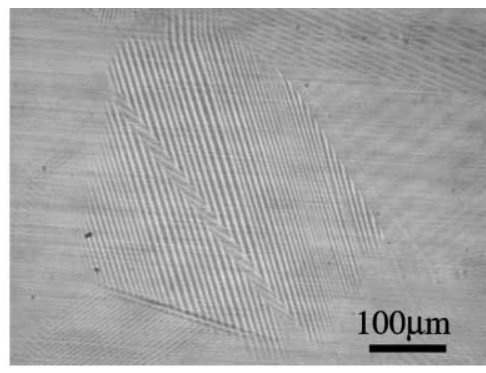

(c) Fe- 22at $\%$ Pd 8 at $\% \mathrm{Pt}$

Fig. 2. fct Martensite morphology for Fe-Pd and Fe-Pd-Pt alloys.

Fig. 3 shows the temperature dependency of Young's modulus. Young's modulus was determined from the slope of the stress-strain response up to $0.05 \%$ of the total strain. Young's moduli of $\mathrm{Fe}-\mathrm{Pd}-\mathrm{Pt}$ alloy are generally larger than that of $\mathrm{Fe}-\mathrm{Pd}$ alloy in the temperature range above Ms temperature. The modulus of Fe-Pd alloy decreases with a decrease of temperature, as is reported as a lattice softening $[9,10]$ and shows a steep change in its temperature dependency around Ms temperature. Although the moduli for $\mathrm{Fe}-\mathrm{Pd}-\mathrm{Pt}$ alloys also show the temperature dependency similar to in $\mathrm{Fe}-\mathrm{Pd}$ alloy, their dependency are weak. The steep modulus change around Ms temperature also becomes dull in the $\mathrm{Fe}-\mathrm{Pd}-\mathrm{Pt}$ with larger $\mathrm{Pt} / \mathrm{Pd}$ composition ratios. Young's moduli at low temperatures are almost same among all the alloy compositions.

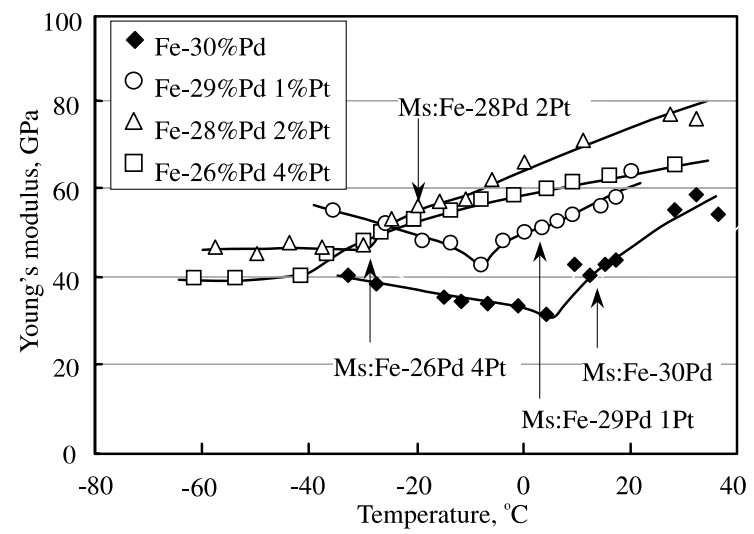

Fig. 3. Dependency of Young's modulus on test temperature.
The stress induced transformation was also observed in $\mathrm{Fe}-\mathrm{Pd}-\mathrm{Pt}$ alloys as in $\mathrm{Fe}-\mathrm{Pd}$ alloy [11]. The stress induced martensite and its recovery after unloading are observed in the tensile tests just above Ms temperature, Fig. 4 where (a-1) through (a-4) correspond to the filled points in the stressstrain curve of Fe-29at.\%Pd1at.\%Pt alloy, Fig. 5. The volume fraction of the martensite phase increased during increasing stressing, i.e. (a-2) to (a3). After unloading to point (a-4) in Fig. 5, most of the martensite phase disappeared except some traces. Comparing with the initial stage of the loading (a-1), the grain boundary is conspicuous, because this specimen was loaded up to a larger stress of $280 \mathrm{MPa}$. Fig. 4(b) shows a similar morphology for Fe-26at.\%Pd4at.\%Pt. This observation was carried out in the loading up to 53 $\mathrm{MPa}$ for Young's modulus measurement. Two kinds of the martensite variants are induced at the stress of $53 \mathrm{MPa}(\mathrm{b}-2)$. During the unloading, one of them disappeared (b-3) and another vanished at $14 \mathrm{MPa}$ (b-4). At this small loading level, the stress induced martensite is recovered without any traces after the unloading (b-4). This completely reversible transformation is not observed at a large scale in the specimen, thus not contributing to the overall stress-strain relation. All alloys loaded up to about $50 \mathrm{MPa}$ showed the completely linear stress-strain curves that exhibited the unloading lines overlaid on the loading lines.

The stress-strain curves of $\mathrm{Fe}-\mathrm{Pd}$ and $\mathrm{Fe}-\mathrm{Pd}-\mathrm{Pt}$ alloys taken within the temperature range between Ms and Af are shown in Fig. 5. Each specimen was subjected to the same maximum stress of $280 \mathrm{MPa}$ and unloaded. Specimens after unloading to zero 
(a)

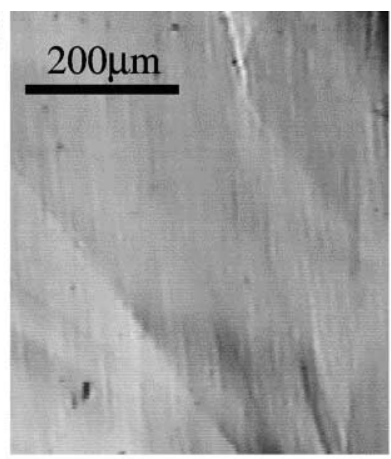

(a-1) $\sigma=7 \mathrm{MPa}$

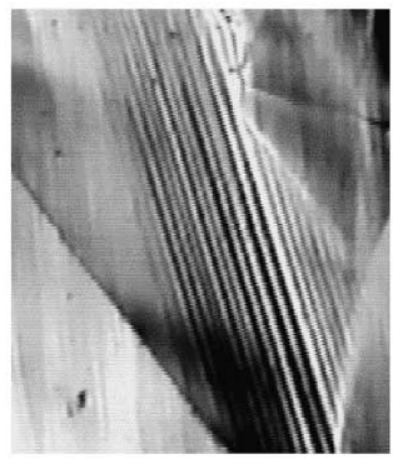

(a-3) $\sigma=144 \mathrm{MPa}$

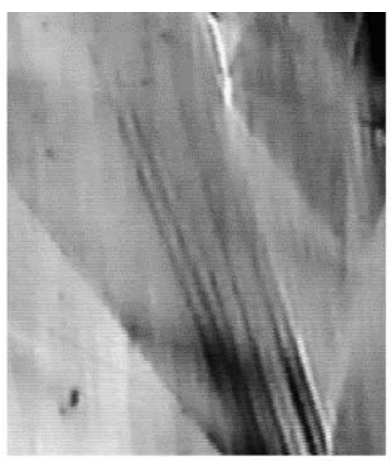

(a-2) $\sigma=44 \mathrm{MPa}$

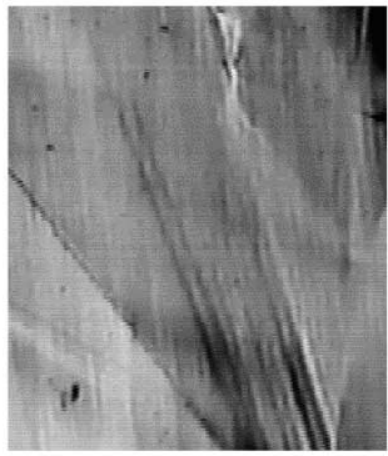

(a-4) $\sigma=7 \mathrm{MPa}$ (b)

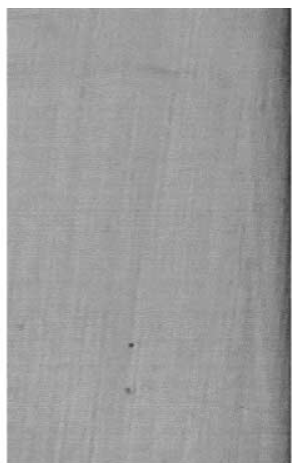

(b-1) $\sigma=14 \mathrm{MPa}$

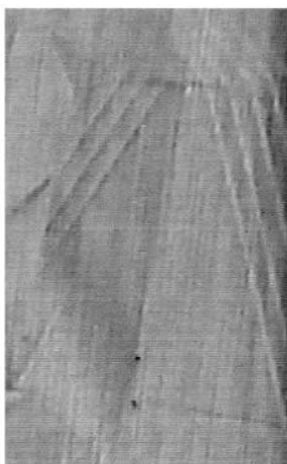

(b-3) $\sigma=48 \mathrm{MPa}$

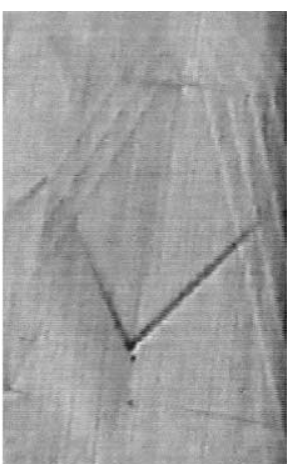

(b-2) $\sigma=53 \mathrm{MPa}$

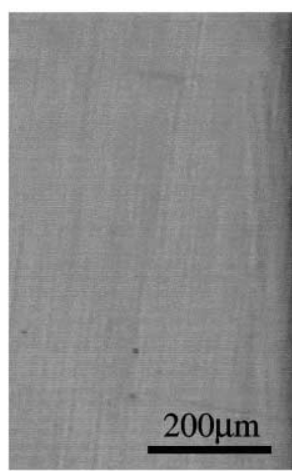

(b-4) $\sigma=14 \mathrm{MPa}$

Fig. 4. Stress induced martensite and their recovery in unloading observed in the tensile test for Fe-Pd-Pt alloys: (a) Fe-29at.\% Pdlat.\%Pt at $3{ }^{\circ} \mathrm{C}$; (a-1)-(a-4) correspond to the points on the stress/strain relation in Fig. 5, (b) Fe-26at. $\% \mathrm{Pd} 4 \mathrm{at} . \% \mathrm{Pt}$ at $-23{ }^{\circ} \mathrm{C}$; observed in Young's modulus measurement.

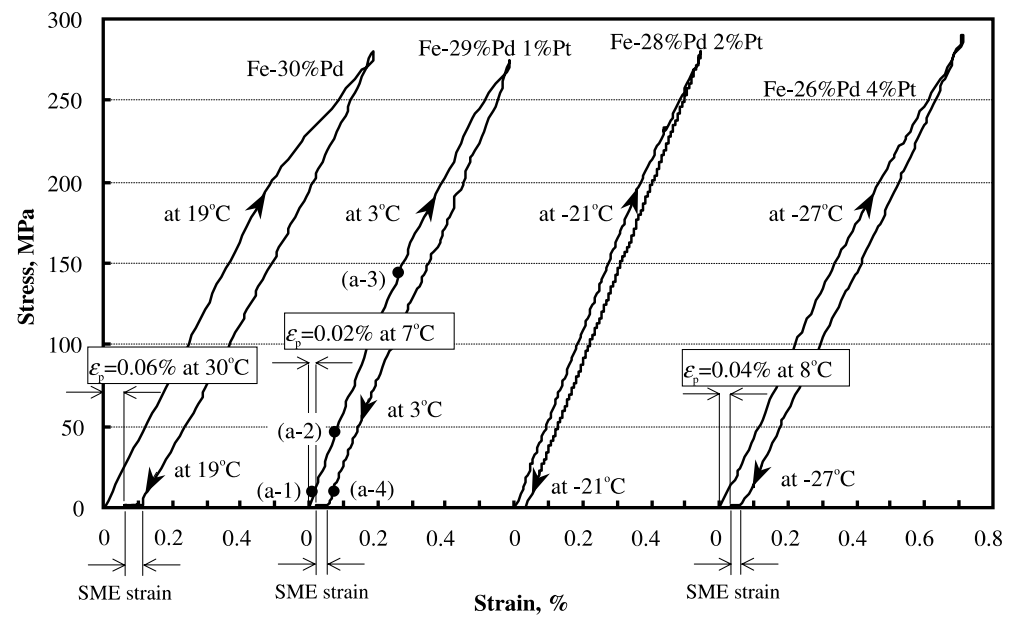

Fig. 5. Stress/strain relations obtained by the tensile tests at Ms-Af temperature range where permanent strain $\left(\varepsilon_{\mathrm{p}}\right)$ after heating up for $\mathrm{Fe}-\mathrm{Pd}$ and $\mathrm{Fe}-\mathrm{Pd}-\mathrm{Pt}$ alloys are also shown. (Note: points from (a-1) to (a-4) on the stress/strain curve for $\mathrm{Fe}-29 \mathrm{at} . \% \mathrm{Pd} 1 \mathrm{at} . \% \mathrm{Pt}$ correspond to the observations shown in Fig. 4). 
stress exhibited the residual strain which presumably is the sum of transformation strain and permanent plastic strain $\varepsilon_{\mathrm{p}}$. In order to examine the resistance of the slip deformation, the shape memory effect (SME) strain was recovered upon heating to the temperature just above Af. The Fe$\mathrm{Pd}$ alloy exhibited the permanent strain $\varepsilon_{\mathrm{p}}$ of $0.06 \%$ after recovering. The permanent strain $\varepsilon_{\mathrm{p}}$ of $0.02 \%$ for $\mathrm{Fe}-29$ at.\%Pdlat.\%Pt was smaller than that for the $\mathrm{Fe}-\mathrm{Pd}$ alloy. Among these three alloys, $\mathrm{Fe}-$ 28at.\%Pd2at.\%Pt alloy showed the smallest permanent strain $\varepsilon_{\mathrm{p}}$ after recovering, which was too small to be measured. These experimental results indicate that the replacement of Pd by Pt contributed to the increase in the resistance of slip deformation. On the other hand, Fe-26at.\%Pd4at.\%Pt alloy exhibited both bet and fct martensite transformations under applied stress up to $280 \mathrm{MPa}$ at temperature just above fcc/fct Ms temperature. The permanent strain includes both the plastic strain and the transformation strain of the bct martensite, because of its non-thermoelastic character.

\section{Conclusive remarks}

The replacement of Pd with $\mathrm{Pt}$ for $\mathrm{Fe}-30 \mathrm{at} . \% \mathrm{Pd}$ alloy decreased the fcc/fct $\mathrm{Ms}$ temperature. Strengthening due to the solution hardening with $\mathrm{Pt}$ was observed. The SMC was investigated for $\mathrm{Fe}-(x \mathrm{Pd} y \mathrm{Pt})_{x+y=30}$ at. $\%$ alloys up to 4 at. $\% \mathrm{Pt}$ below the Af temperatures. Above the Af temperatures, the stress induced fct martensite in several grains for each alloy completely disappeared due to the reverse transformation by unloading.

\section{Acknowledgements}

This work was supported by the Darpa/ONR contract on CHAP program (N00014-00-1-0520) where Dr. Roshdy Barsoum of ONR and Dr. E. Garcia of Darpa are the program monitors and NEDO contract on smart materials to the University of Washington. The stimulative discussions with Drs. H. Kato and T. Mori, University of Washington, were greatly appreciated.

\section{References}

[1] Webster KJ, Ziebeck KRA, Town SL, Park SL. Philos Mag B 1984;77:295-310.

[2] Chernenko VA, Cesari E, Kokorin VV, Vitenko IN. Scripta Metall 1995;33:1239-44.

[3] Dunne DP, Wayman CM. Metall Trans 1973;4:137-45.

[4] Muto S, Oshima R, Fujita FE. Metall Trans A 1988;19A: 2931-6.

[5] Maki T, Kobayashi K, Minato M, Tamura I. Scripta Metall 1984;18:1105-9.

[6] Sohmura T, Oshima R, Fujita FE. Scripta Metall 1980; 14:855-6.

[7] Oshima R. Scripta Metall 1981;15:829-33.

[8] Tickle R, James RD. J Magn Magn Mater 1999;195:62738.

[9] Sugiyama M, Harada S, Oshima R. Scripta Metall 1985; 19:312-7.

[10] Muto S, Ohshima R, Fujita FE. Acta Metall Mater 1990; 4:685-94.

[11] Kato H, Liang Y, Taya M, unpublished work. 